\title{
Infusion of Iloprost, a prostacyclin analogue, for treatment of Raynaud's phenomenon in systemic sclerosis
}

\author{
N J McHUGH, ${ }^{1}$ M CSUKA, ${ }^{2}$ H WATSON, ${ }^{3}$ G BELCHER, ${ }^{3}$ A AMADI, \\ E F J RING, ${ }^{1} \mathrm{C} M$ BLACK, ${ }^{2}$ AND P J MADDISON ${ }^{1}$
}

From the 'Royal National Hospital for Rheumatic Diseases, Bath; the 'West Middlesex Hospital, Isleworth, Middlesex; and ${ }^{3}$ Schering Health Care Ltd, West Sussex, UK

SUMMARY Iloprost, a stable prostacyclin analogue, was given by intravenous infusion to 29 patients with severe Raynaud's phenomenon, 26 of whom had systemic sclerosis (SS), and compared with placebo infusion in a double blind crossover trial. Iloprost significantly lessened the number and the severity of attacks compared with placebo. Nine patients expressed a preference for effectiveness of treatment, eight of these in favour of Iloprost. Thermography failed to show any long term effect of Iloprost. Side effects of headache, flushing, nausea, and vomiting were common, and the inconvenience of intravenous administration may limit its routine use.

Severe Raynaud's phenomenon is often the most troublesome manifestation of SS and is difficult to treat successfully. Increased platelet activation may be a factor in its causation. ${ }^{1}$ The use of prostanoids, prostaglandin $\mathrm{E}_{1}{ }^{2}$ and prostacyclin. ${ }^{3}$ which are potent vasodilators and inhibit platelet aggregation, has been shown to alleviate symptoms in many patients. Rapid metabolism in vivo, however, may limit their therapeutic potential. Iloprost is a chemically stable carbacyclin derivative of prostacyclin with a half life exceeding that of prostacyclin by a factor of 10.5 It has been shown to be more potent than prostacyclin as an antiplatelet agent but induces less vasodilatation. ${ }^{6}$ It inhibits platelet aggregation in patients with progressive systemic sclerosis (PSS) when given by a five hour intravenous infusion. $^{7}$

A pilot study using Iloprost infusion in 12 patients with secondary Raynaud's phenomenon showed improvement in symptoms and an increase in digital blood flow for up to five weeks after therapy (unpublished data). We chose to assess the effectiveness of Iloprost compared with placebo in a larger number of patients with severe Raynaud's phenomenon secondary to PSS in a randomised

Accepted for publication 22 June 1987.

Correspondence to Dr N J McHugh. Royal National Hospital for Rheumatic Diseases. Upper Borough Walls. Bath BAl 1RL. double blind crossover trial. As symptomatic improvement of Raynaud's phenomenon has been shown to correlate well with thermographic improvement, ${ }^{8}$ measurement of digital temperature gradients by thermography was included in the study.

\section{Patients and methods}

Twenty nine patients ( 25 female, four male) with severe Raynaud's phenomenon, all suffering at least 12 attacks per week, were recruited for the study conducted during the winter months, January to May 1986. Twenty six patients had PSS and three 'idiopathic' Raynaud's phenomenon (Table 1). Patients were randomly allocated to receive either Iloprost or placebo infusion in a double blind crossover trial. Each treatment consisted of three six-hour infusions of Iloprost or placebo on three successive days with six weeks between treatment periods. The medication consisted of Iloprost (ZK 36374) or placebo administered through a peripheral venous cannula via a syringe pump controller. The dose of Iloprost was $2.0 \mathrm{ng} / \mathrm{kg} / \mathrm{min}$ and could be reduced by increments of $0.5 \mathrm{ng} / \mathrm{kg} / \mathrm{min}$ dependent upon the tolerance of the patients to the side effects associated with the infusions.

A S S E S S M ENTS

Assessments were made one day before treatment 
and one day, two weeks, and six weeks after each treatment. Patients kept diary cards the week before the first treatment and over the 12 week study period. Patients recorded the date, the duration, and the severity on a scale of 1-3 for each Raynaud's attack they suffered as well as whether the attack was painful or painless. For the purposes of analysis a painless attack was given a score of 1 and a painful attack a score of 2 . At each assessment the patient reported any change in his or her condition and at the end of the study the effectiveness of both treatments. Active lesions present on hands and feet were recorded at each assessment.

\section{T H E R M O G R A P H Y}

Thermography was performed at each assessment as previously described. ${ }^{9}$ For each scan the mean temperature of the dorsal hand and fingers was recorded with a Heimann KT41 infrared radiometer positioned $2 \mathrm{~cm}$ from the skin, or by infrared thermography (AGA 782) and the values calculated by image processing using a computer and video display. These measurements were repeated 10 minutes after cold stress. By subtracting the values of the temperature of the distal phalanges from the dorsum of the hand a thermal gradient was obtained. Thermal gradients for resting conditions (pre-cold stress) and for after cold stress (post-cold stress) were obtained. A combined thermal gradient was also derived by adding the pre- and post-cold stress measurements.

STATISTICAL METHODS

The study was analysed by the method of Hills and Armitage ${ }^{10}$ using the Van der Waerden test, the sign test, and the $\chi^{2}$ test.

\section{Results}

DEMOGRAPHIC DATA

There were no significant differences between the group who received Iloprost first and the group who received placebo first (Table 1). Twenty six patients fulfilled American Rheumatism Association criteria for SS. " Of these, 14 had at least four features of the 'CREST' variant of SS, with anticentromere antibodies detected in the serum of six, and two patients had overlap features of mixed connectives tissue disease (MCTD) with serum containing antiU1RNP. Three additional patients had severes Raynaud's phenomenon without evidence of underlying connective tissue disease, though the serum from one of these patients contained anti-Scl-70.

Twenty five out of 29 patients completed the fulp

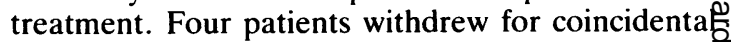
medical or social problems, three not being associ- $\rightarrow$ ated with therapy.

DIARY CARD DATA

Twenty out of 25 patients who completed the study? maintained their diaries regularly and accurately enough for them to be analysed. There were nơ significant differences in the baseline diary card datw between the two treatment groups (Table 2).

Table 1 Details of patients randomly assigned to treatmen? groups

\begin{tabular}{|c|c|c|c|}
\hline & $\begin{array}{l}\text { All } \\
\text { patients }\end{array}$ & $\begin{array}{l}\text { Iloprost } \\
\text { first }\end{array}$ & $\begin{array}{l}\text { Placebo } \\
\text { first }\end{array}$ \\
\hline Mean age (years) & $56 \cdot 6$ & $54 \cdot 7$ & $58 \cdot 6$ \\
\hline Women & 25 & 13 & 12 \\
\hline Men & 4 & 2 & 2 \\
\hline PSS & 26 & 13 & 13 \\
\hline CREST* & 14 & 6 & 8 \\
\hline non-CREST & 10 & 6 & 4 \\
\hline MCTD* & 2 & 1 & 1 \\
\hline Primary Raynaud's disease & 3 & 2 & 1 \\
\hline ANA positive* & 24 & 12 & 12 \\
\hline ACA positive* & 7 & 3 & 4 \\
\hline $\begin{array}{r}\text { Years since onset of } \\
\text { Raynaud's disease }\end{array}$ & $11 \cdot 1$ & $9 \cdot 6$ & $12 \cdot 6$ \\
\hline
\end{tabular}

${ }^{*}$ CREST $=$ calcinosis, Raynaud's phenomenon, oesophageal dyso motility, sclerodactyly, telangiectasia; $M C T D=$ mixed connectiv? tissue disease; $\mathrm{ANA}=$ antinuclear antibody: $\mathrm{ACA}=$ anticentromer antibody.

Table 2 Comparison of the effects of lloprost and placebo on the mean percentage change from baseline for number, duration, severity, and proportion of painful attacks of Raynaud's disease for weeks 2-6 of the study

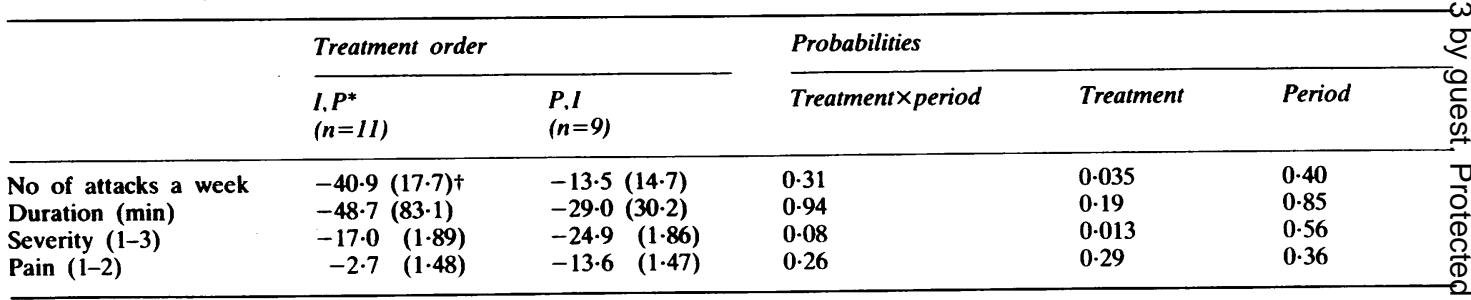

*I=Iloprost; $\mathbf{P}=$ placebo.

†Values are means (I-P) with absolute baseline values given in parentheses. 
Table 2 shows the percentage change from baseline for number, duration, severity, and proportion of painful attacks, comparing placebo and Iloprost for the two groups receiving either Iloprost or placebo first. A negative sign indicates greater benefit from Iloprost than from placebo. Probabilities are given for a treatment period interaction (e.g., hangover effect of the drug beyond six weeks of the single drug effect), a treatment effect (i.e., one treatment more effective than another), and period effects (i.e., the first or second period more effective than the other, independent of the drug treatment). Week 1 after treatment was excluded from the analysis as there was a significant period effect.

Iloprost was significantly more effective than placebo in reducing the number of attacks $(p=0.035)$ and the severity of attacks $(p=0.013)$ of Raynaud's phenomenon for weeks $2-6$ after treatment, and this trend was shown throughout the study period. The duration of attacks in general was reduced more by Iloprost than placebo, though this only reached statistical significance at week 5 after treatment. No difference between Iloprost and placebo was shown in the proportion of painful attacks.

Over the six week period (Fig. 1) patients receiving Iloprost showed an average reduction in the number of attacks of $30 \%$ compared with a placebo response of $2 \%$. Duration of attacks was reduced by an average of $9 \%$ by Iloprost, whereas with placebo the duration of attacks was increased by $26 \%$ over the six week period. Iloprost reduced the severity of attacks by $20 \%$ and during the placebo period severity was reduced by $1 \%$ (Fig. 2 ).

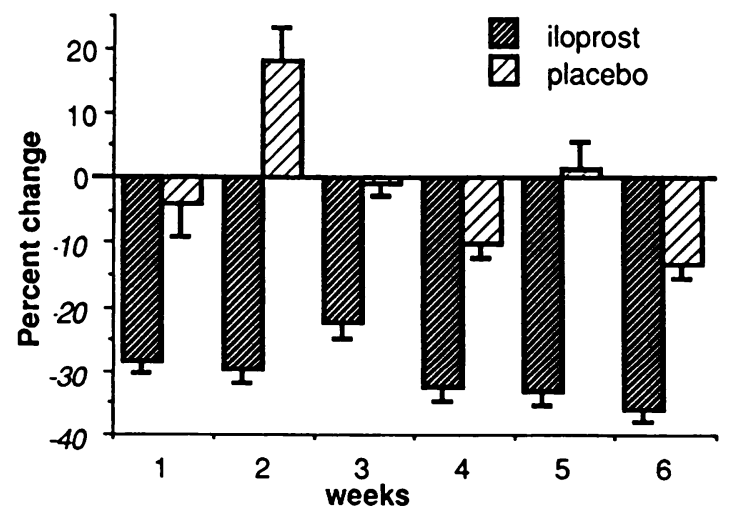

Fig. 1 Percentage change in the number of attacks of Raynaud's disease for six weeks after three infusions of Iloprost or placebo (values were calculated combining results from the two periods of the crossover study).

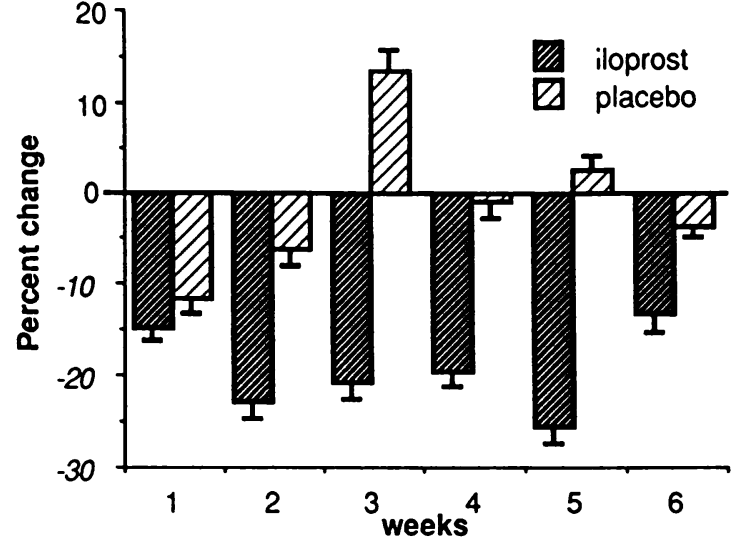

Fig. 2 Percentage change in the severity of attacks of Raynaud's disease for six weeks after three infusions of Iloprost or placebo (values were calculated combining results from the two periods of the crossover study).

The proportion of painful attacks was reduced by $16 \%$ with Iloprost compared with $11 \%$ with placebo.

\section{TH E R M O G R A P H Y}

Patients with Raynaud's phenomenon normally show a negative thermal gradient between the dorsum of the hand and the phalanges, which increases after cold stress, in contrast with the control population where the thermal gradient is slight and may become positive through reactive hyperaemia. The only statistically significant difference between the effects of placebo and Iloprost was the difference between thermal gradients before and after the cold stress the day after the third infusion. where the Iloprost group showed less vasospastic response to the cold stress test than the placebo group $(\mathrm{p}<0 \cdot 02)$. No long term difference between the two treatments was shown.

\section{PATIENT ASSESSMENT OF EFFECTIVENESS}

When patients' opinion of their condition was scored for each assessment $(1=$ definitely improved to $5=$ definitely worsened) and the effect of the treatments compared for each equivalent assessment, Iloprost was better than placebo at all assessments, and this was statistically significant for week 6 after treatment $(p<0 \cdot 01)$. At the end of the study patients were asked if the treatments had been beneficial. Of the nine patients who considered one treatment had been helpful whereas the other treatment had not, eight viewed Iloprost as beneficial and only one considered placebo as beneficial. This is a statistically significant result $(p=0.0456$, sign test). 


\section{SKIN LESIONS}

At each visit a record of active lesions was made. Fifteen of 29 patients had active skin lesions at some stage, with finger ulceration in eight, painful fissures in four, and chilblains in three. Several patients in addition had more chronic dystrophic finger tip lesions with calcinosis. Over the period of the study no difference could be detected between the effect of the two treatments on this criterion.

It was notable that the two youngest patients, both women, aged 25 and 31 respectively, with disease duration less than two years, had a marked improvement of skin lesions with Iloprost but not with placebo. One had a large ischaemic finger tip lesion which had failed to respond to conventional treatment but healed with Iloprost and the other with primary Raynaud's phenomenon had severe chilblains on both feet, which also responded to Iloprost.

DRUG TOLERANCE, SIDE EFFECTS, AND WITH DR A W A LS

Thirteen of 26 patients tolerated a dosage of Iloprost of $2.0 \mathrm{ng} / \mathrm{kg} / \mathrm{min}$. In five patients the dosage was reduced to $1.5 \mathrm{ng} / \mathrm{kg} / \mathrm{min}$, in seven patients to 1.0 $\mathrm{ng} / \mathrm{kg} / \mathrm{min}$, and one patient could only tolerate 0.5 $\mathrm{ng} / \mathrm{kg} / \mathrm{min}$. Side effects were common, with headache $(18 / 26)$, facial flushing $(6 / 26)$, nausea (14/26), vomiting (7/26), and diarrhoea (5/26) occurring in all but three of 26 patients. Reduction of the dose and prophylactic use of an antiemetic, however, permitted continuation of treatment in all cases. There were no long term adverse effects and no effects on routine haematological or biochemical parameters.

Four patients withdrew from the study. Three of those had received placebo infusions only before withdrawing, two withdrawing because of concurrent illness and one because of his inability to attend owing to adverse weather conditions. One patient withdrew from the group that received Iloprost first. After the first treatment, during which this patient developed diarrhoea, her symptomatology was improved and she felt a second treatment was not necessary.

\section{Discussion}

We have shown that Iloprost, given by three sixhour infusions on successive days to patients with PSS significantly reduces the frequency and severity of attacks of Raynaud's phenomenon compared with placebo. The average reduction in frequency of Raynaud's attacks for the six weeks after Iloprost infusions was $30 \%$ and the reduction in severity of attacks $20 \%$. Subjective patient response to treatment in terms of benefit or other- - . wise similarly showed Iloprost to be more effective $\overrightarrow{\vec{F}}$ than placebo. Of nine patients who reported only? one of the treatments effective, eight of these werec in favour of Iloprost.

These results are in accord with results from $\vec{\sigma}_{\bar{\delta}}$ reported studies using native prostacyclin ${ }^{34}$ and with results from a previous double blind study usinge Iloprost. ${ }^{8}$ In the latter study both patients' symp- $-\overrightarrow{0}$ toms were improved and digital blood flowsmeasured using laser-Doppler techniques were shown to be improved for up to five weeks aftero Iloprost treatment. In a more recent open study? digital peripheral vascular resistance measured using plethysmographic methods was found to be decreased in patients with Raynaud's phenomenon for $6-10 t$ weeks after Iloprost treatment. ${ }^{12}$ In the present? study no changes in digital thermal gradients beforeand after cold stress were detected after Iloprost or placebo. The thermal gradient is a good objective measure of reduced digital blood flow in patients with Raynaud's phenomenon. It may not reflect the subjective changes produced by this treatment. The measurement of rewarming times by thermography ${ }^{\circ}$ has been suggested as an alternative method for distinguishing changes in vasospasticity of the digitas vessels. ${ }^{9}$

There was no difference between Iloprost andहै placebo in healing ischaemic lesions, though the crossover design and short follow up period of the present study make interpretation difficult. There were a few notable exceptions, with the two youngest patients also with the shortest duration op disease showing definite improvement in healing of active lesions with Iloprost but not with placebo? suggesting that Iloprost may be more effective foㅡㅡㅁ this category of patient.

Side effects during Iloprost infusion were com $\frac{\widehat{\rho}}{3}$ mon. Flushing and headache at least could be attributed to the vasodilative action of Iloprost? There were no hypotensive events, no longlastin adverse effects, and lowering of the infusion rate and use of an antiemetic prophylactically allowe continuation of treatment in all cases.

In conclusion, Iloprost is effective in reducing th\& number and severity of Raynaud's attacks in PSS fof up to six weeks after infusion and may improve active skin lesions in some cases. Its routine use limited by the common occurrence of unpleasan side effects and the inconvenience of intravenous administration. Alternative treatment regimens using Iloprost may prove to be as effective and mor acceptable.

The authors gratefully acknowledge Schcring Health Care Limito for supplying Iloprost (ZK 36374) and Mr A Pcarce for statisticat 
analysis of the results. We also thank Mrs J Wright for typing the manuscript.

\section{References}

1 Blunt R J, George A J, Hurlow R A, Strachan C J L, Stuart J. Hyperviscosity and thrombotic changes in idiopathic and secondary Raynaud's syndrome. Br J Haematol 1980; 45: 651-8.

2 Clifford P C, Martin M F R, Sheddon E J, Kirby J D, Baird R N, Dieppe P A. Treatment of vasospastic disease with prostaglandin E. Br Med J 1980; 281: 1031-4.

3 Belch J J F, Drury J K, Capell H, et al. Intermittent epoprostenol (prostacyclin) infusion in patients with Raynaud's syndrome: a double-blind controlled trial. Lancet 1983; i: 313-5.

4 Dowd P M, Martin M F R, Cooke E D, et al. Treatment of Raynaud's phenomenon by intravenous infusion of prostacyclin (PGI $)$ Br J Dermatol 1982; 106: 81-9.

5 Krause W, Krais Th. Pharmacokinetics and pharmacodynamics of the prostacyclin analogue Iloprost in man. Eur $J$ Clin Pharmacol 1986; 30: 61-8.

6 Schror K, Davis H, Matzky R, Ohlendorf R. The anti platelet and cardiovascular actions of a new carbocyclin derivative (ZK
36374) equipotent to $\mathrm{PGI}_{2}$ in vitro. Naunyn Schmiedebergs Arch Pharmacol 1981; 316: 252-5.

7 Keller J, Kaltenecker A, Schricher K T, Neidhart B, Hornstein $O \mathrm{P}$. Inhibition of platelet aggregation by a new stable prostacyclin introduced in therapy of patients with progressive scleroderma. Arch Dermatol Res 1985; 277: 323-5.

8 Kyle V, Parr G, Salisbury R. Page Thomas P. Hazleman B. Prostaglandin $\mathrm{E}_{1}$ vasospastic disease and thermography. Ann Rheum Dis 1985; 44: 73-8.

9 Ring E F J, Porto L O, Bacon P A. Quantitative thermal imaging to assess inositol nicotinate treatment for Raynaud's syndrome. J Int Med Res 1981; 9: 393-400.

10 Hills M, Armitage P. The two-period crossover clinical trial. $\mathrm{Br}$ J Clin Pharmacol 1979; 8: 7-20.

11 Masi A T, Rodnan G P. Medgser T A J, et al. Preliminary criteria for the classification of systemic sclerosis (scleroderma). Arthritis Rheum 1980; 23: 581-90.

12 Rademaker M, Meyrick-Thomas R H, Provost G, Beacham J A, Cooke E D, Kirby J D. Prolonged increase in digital blood flow following Iloprost infusion in patients with systemic sclerosis. Postgrad Med J (in press). 